\title{
PERPETUATION OF STEM CELLS IN THE EYE
}

\author{
JAMES D. ZIESKE \\ Boston, Massachusetts, USA
}

\begin{abstract}
SUMMARY
In adult tissues, cell numbers are maintained through a subpopulation of cells termed stem cells, characterised in part by a high capacity of self-renewal, slow cell cycle, and resistance towards differentiation. Stem cells are capable of asymmetric division and able to maintain their position in a particular microenvironment or niche. In the cornea, epithelial stem cells are believed to reside in the basal cell layer of the limbal epithelium. We consider the question of how stem cells are perpetuated in the limbus without entering the pathway of terminal differentiation. This perpetuation could presumably be the result of extrinsic properties of the limbal zone creating a 'stem cell niche', or of intrinsic properties of the cells. For example, limbal basal cells contain four- to fivefold higher levels of epidermal growth factor receptor than central corneal basal cells, suggesting that high levels of epidermal growth factor receptor help maintain the limbal basal cells in an undifferentiated stem cell state.
\end{abstract}

\section{DIFFERENTIATION OF A STEM CELL}

In the adult organism, many tissues undergo rapid and continuous cell turnover. These tissues, which include simple and stratified epithelium as well as the haemopoietic system, must repopulate and simultaneously maintain the integrity of the tissue. The cells ultimately responsible for repopulation are termed 'stem cells' and can be defined as any cell with a high capacity for selfrenewal extending throughout adult life. ${ }^{1}$ These cells are a small subpopulation of the total tissue and have been estimated to make up from $0.5 \%$ or less to $10 \%$ of the total cell population. ${ }^{2,3}$ Stem cells are thought to share a common set of characteristics including high proliferative potential and a long cell cycle. Perhaps the most particular and least understood property of stem cells is the capacity to undergo asymmetric cell division. This property allows one of the daughter cells to remain a stem cell while the other daughter cell is slightly more differentiated. These daughter cells have been termed 'transit'" or 'transient amplifying' (TA) cells. ${ }^{4}$ TA cells have a limited proliferative potential and are considered the initial step of a pathway that results in terminal differentiation.

Correspondence to: James D. Zieske, PhD, Schepens Eye Research Institute, 20 Staniford Street, Boston, MA 02114, USA.

\section{LOCALISATION OF CORNEAL EPITHELIAL STEM CELLS IN THE LIMBUS}

In the cornea, stem cells are thought to be located in the limbus, the transition zone between corneal and conjuctival epithelium (Fig. 1). The concept that epithelial cells in the limbal region are involved in the renewal of corneal epithelium was reported first by Davanger and Evensen in 1971. ${ }^{5}$ They observed that pigmented cells in the limbus migrated centripetally towards the central cornea. This observation evolved into the hypothesis that stem cells are
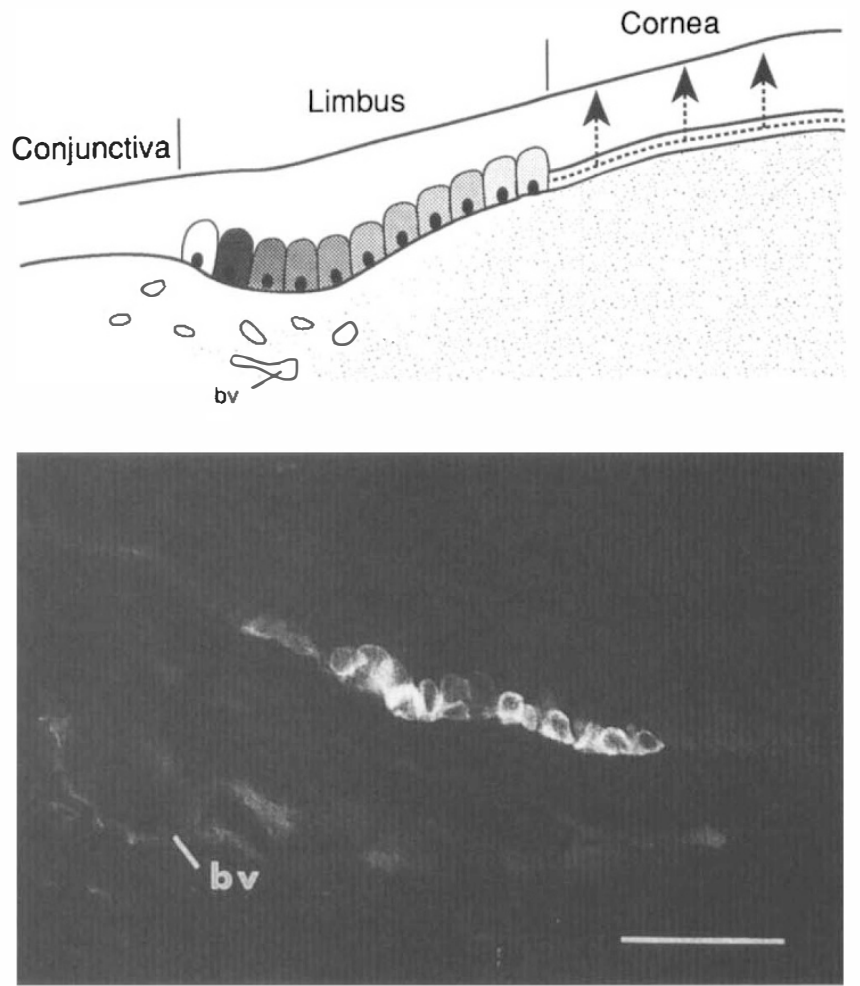

Fig. 1. Top: Diagrammatic demonstration of the limbal zone. Blood vessels ( $b v$ ) are localised directly subjacent to the limbal basal cells. A stem cell (darkest shad ing) is indicated along with a gradient (decreasing level of shad ing) of undifferentiated cells with some stem-like characteristics. These cells migrate (arrows) centripetally and apically to populate the central cornea. Bottom: Immunolocalisation of $\alpha$-enolase using $4 G 10.3$ in rat cornea. Note the intense bind ing in the limbal basal cells. Scale bar represents $50 \mu \mathrm{m}$. 

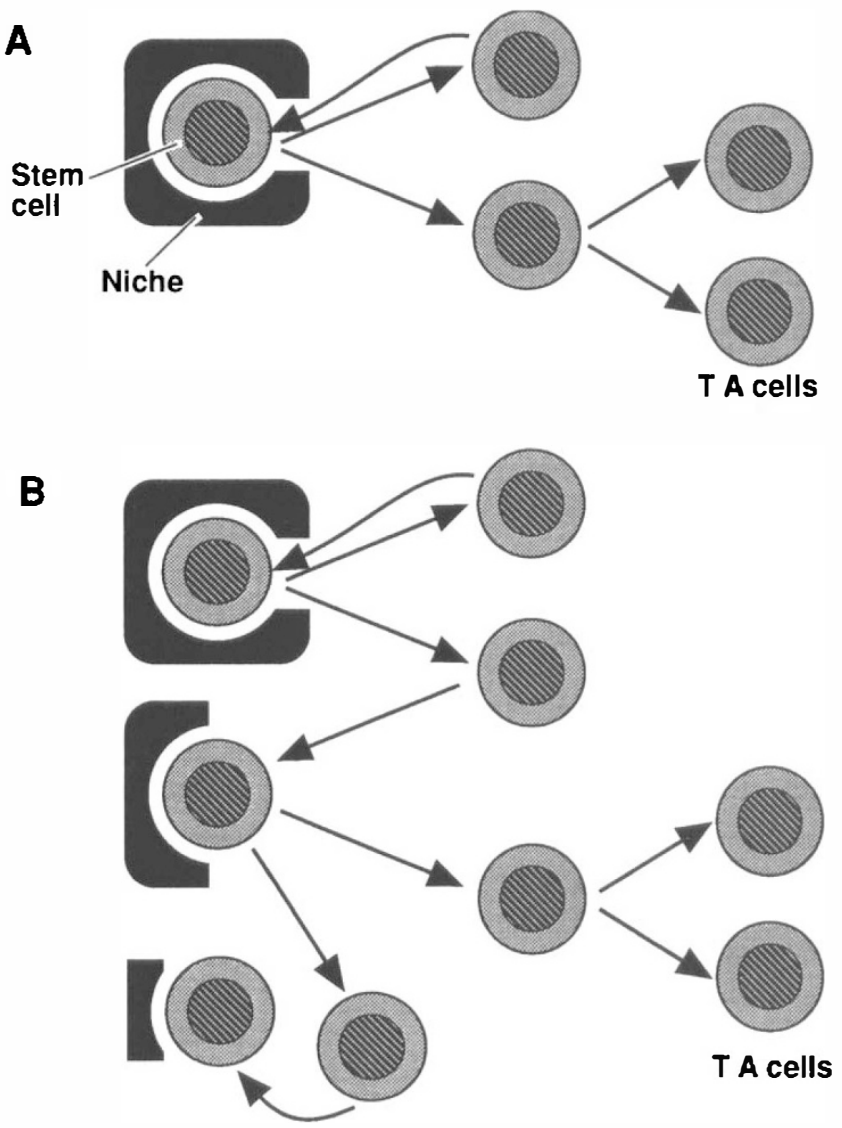

Fig. 2. Diagrammatic representation of the niche hypothesis. (A) Modification of the hypothesis proposed by Schofield. ${ }^{15}$ In this hypothesis, the stem cell is maintained in a microenvironment 'niche' that prevents the cell from entering the differentiation pathway. In this model, one daughter cell re-enters the niche while the other differentiates and becomes a TA cell. $(B)$ In an alternative model, following division of the stem cell the daughter cells can either re-enter the stem cell niche or enter a less advantageous niche that allows the cell to remain undifferentiated and retain stem-like characteristics. Following division, these cells can enter the differentiation pathway or remain in an undifferentiated stem-like state. This model allows cells to express a gradient of characteristics ranging from 'true' stem cell to TA cell, to terminally differentiated cell. The model is proposed to explain experimental data suggesting that most limbal basal cells have undifferentiated characteristics while only 10-20\% appear to be stem cells as indicated by thymidine label retention.

localised in the basal cell layer of the limbus when Schermer et al. ${ }^{4}$ reported that in situ all corneal epithelial cells except limbal basal cells express keratin 3 (K3). This keratin, bound by the monoclonal antibody AE5, is not expressed in undifferentiated cells in culture but is present in post-confluent stratified cultures. These data suggest that $\mathrm{K} 3$ is a differentiation marker and that the lack of expression of $\mathrm{K} 3$ in the limbal basal cells indicates they are less differentiated than the remainder of the corneal epithelium. Other lines of evidence that support the localisation of stem cells in the limbal basal cell layer include: (1) only limbal basal cells retain tritiated thymidine label for long periods, indicating that they have a long cell cycle time; ${ }^{6}$ (2) limbal basal cells have a higher proliferative potential in culture than central corneal epithelial cells; $;^{7-9}$
(3) surgical removal of the limbal region results in healing with non-corneal epithelium; ${ }^{10.11}$ (4) limbal transplants result in regeneration of cornea-like epithelium; ${ }^{12}$ and (5) limbal basal cells respond to central corneal wounds by undergoing cell division as would be expected of stem cells. ${ }^{6.13}$ This review will concern itself with corneal epithelial stem cells; however, stem cells have also been localised in the fornix region of the conjunctiva. ${ }^{14}$

\section{THE IMPORTANCE OF STEM CELL PERPETUATION}

While an ever-increasing amount of information is being reported about the unique properties of the limbal epithelium and limbal zone, which may relate to identifying the corneal epithelial stem cells, little is known about the mechanisms or characteristics that help maintain and perpetuate the stem cells in the limbus. That is, how does the stem cell avoid entering the pathway of terminal differentiation? Thus, this review will address the question of how stem cells are perpetuated. This question has ramifications beyond its basic science aspects. It may also be important in carcinogenesis, where it is currently believed that the stem cell must be the site of the original mutation to allow the formation of a tumour. Also several laboratories are investigating the use of cultured cells to replace damaged corneal epithelium. Obviously the probability of a successful transplant would be enhanced by increased knowledge on how to maintain a stem cell in culture and perpetuate its 'stemness'.

\section{'STEMNESS': EXTRINSIC PROPERTIES}

In an examination of how 'stemness' is maintained, both intrinsic properties (that is, characteristics inherent to the stem cells) and extrinsic properties (that is, characteristics of the environment surrounding the stem cells) must be considered. The maintenance of 'stemness' by extrinsic properties is best explained by a model proposed in 1983 by Schofield. ${ }^{15}$ This hypothesis (Fig. 2) suggests that stem cells exist in an optimal 'niche' or microenvironment that promotes the maintenance of the stem cell in an undifferentiated condition. Following cell division, only one of the daughter cells can re-enter the niche, while the other must enter a less favourable environment that does not protect the cell from entering the pathway of terminal differentiation. Cells leaving the niche still have the capability to divide. In the haemopoietic system the stem cell niche is present in the bone marrow, and the microenvironment is regulated by stromal cells and macrophages. These cells have been postulated to synthesise cytokines and adhesion molecules that may regulate stem cell maintenance. ${ }^{16}$

\section{DOES THE LIMBUS CONTAIN A STEM CELL NICHE?}

If the limbus contains a stem cell niche, the stromal matrix and basement membrane zone would be expected to express properties not seen in the central cornea. The most obvious difference between the limbal zone and central cornea is the presence of blood vessels in the limbus. In the 
human limbus, these vessels help form the palisades of Vogt, allowing a close approach of the vessels to the overlying epithelium. ${ }^{17}$ This proximity of blood vesels provides the potential for increased levels of nutrition in the limbus, along with interaction with blood-derived cytokines. Proximity of blood vessels has been proposed by Cotsarelis et al. ${ }^{6}$ as one of the characteristics of stem cells.

The basement membrane zone of the limbal epithelium has also been shown ultrastructurally to have characteristics not seen in the central cornea. In human limbus, a very rough undulating surface is present, including 'pegs' of stroma extending upwards. ${ }^{17}$ Anchoring fibrils present in these areas extend from the basement membrane and
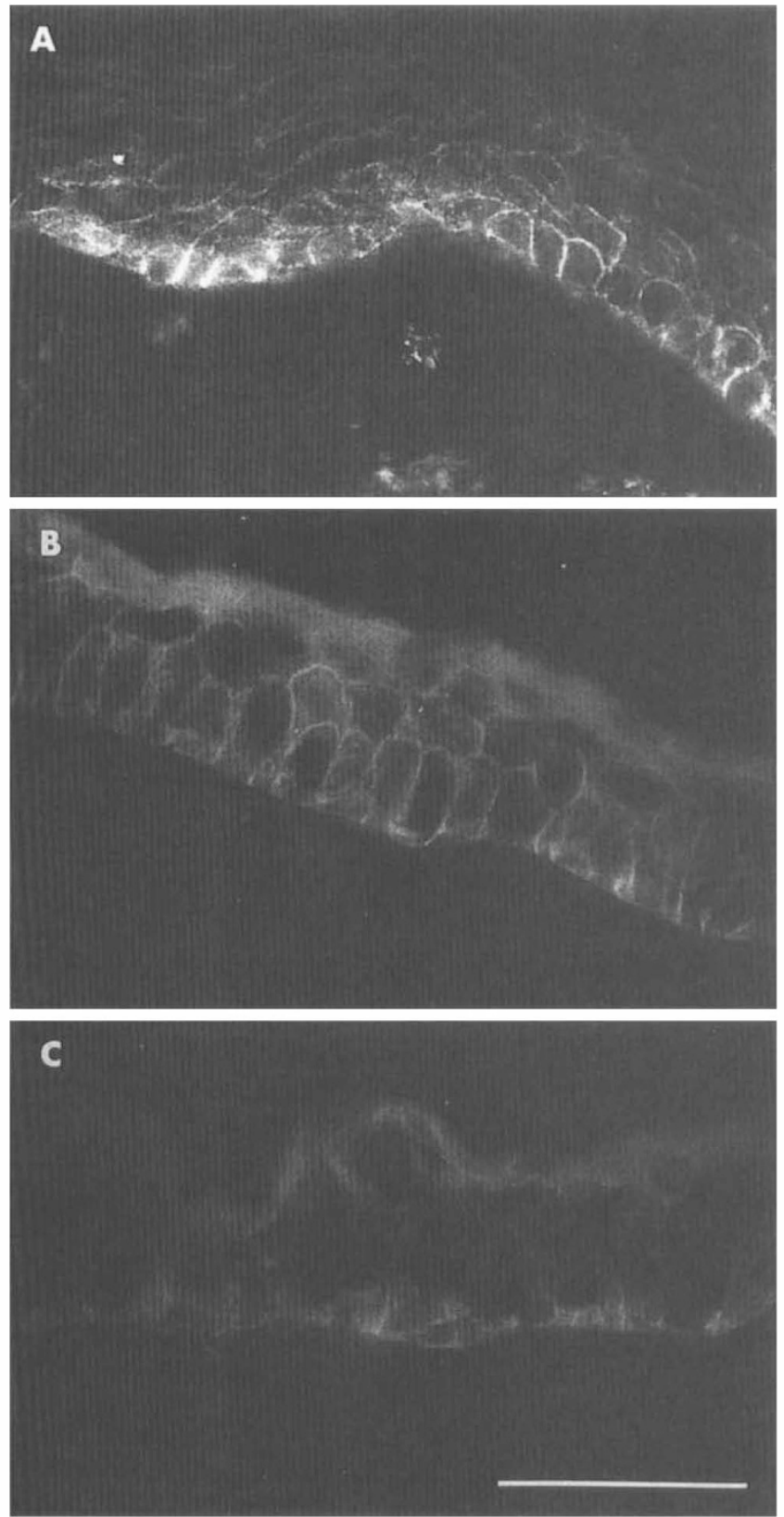

Fig. 3. Immunolocalisation of epithelial growth factor receptor (EGFR) in adult human cornea. (A) The limbal region show's intense membranous labelling of anti-EGFR. (B) The peripheral region shows reduced labelling of anti-EGFR. (C) The central cornea shows a greatly reduced level of immunoreaction of antiEGFR. Scale bars represents $50 \mu \mathrm{m}$. intersect with other anchoring fibrils extending through the stromal pegs. The presence of the stromal pegs, along with the interaction between anchoring fibrils, could potentially form a niche promoting the adherence of the limbal basal cells, protecting them from physical injury and also enhancing their ability to resist movement from the microenvironment.

Along with ultrastructural differences in the basement membrane zone, there appear to be differences in the protein components of the limbal versus central corneal basement membrane. Kolega et al. ${ }^{18}$ reported that type IV collagen can be immunolocalised in the conjunctival and limbal basement membrane but not in the central cornea. In addition, they reported on the immunolocalisation of an antibody, AE27, which bound central corneal basement membrane strongly, conjunctiva weakly, and limbus heterogeneously. They also found that limbal basal cells that expressed $\mathrm{K} 3$, the differentiation marker, were present over basement membrane, binding AE27 at high levels. These data suggest that the basement membrane can direct differentiation with the stem cell niche localised in an area containing high levels of type IV collagen and low levels of the antigen recognised by AE27.

\section{'STEMNESS': INTRINSIC PROPERTIES}

While extrinsic properties may play a role in the maintenance of corneal stem cells, the majority of studies concerning these cells have been examinations of the intrinsic properties of limbal basal cells that distinguish them from central corneal epithelial cells.

Cell culture studies comparing limbal epithelium and central corneal epithelium have shown that limbal cells proliferate faster in culture, ${ }^{7.8}$ that growth factors ${ }^{19}$ and calcium ions ${ }^{20}$ affect the cell types differently, and that limbal epithelium is more resistant to tumour promoters. ${ }^{21}$ Recently, Lindberg et al. ${ }^{9}$ have reported that central corneal epithelial cells senesce in the first or second passage; however, limbal epithelial cells have a much higher proliferative potential (average 23 population doublings). They also found that the transplant of passaged limbal epithelial cells to nude mouse dermis resulted in growth of a limbus-like epithelium. Tissue culture studies can be used to support or argue against the hypothesis that stem cells are maintained by intrinsic properties alone, in that even cultures of limbal epithelium senesce indicating the loss of 'stemness'. However, cultured corneal epithelial ${ }^{9}$ and epidermal $^{22}$ cells can be transplanted resulting in a normalappearing tissue, suggesting that stem cells are retained in culture.

As indicated in Table I, several proteins have been identified that are found in higher concentrations in basal cells of limbal epithelium than in basal cells of central corneal epithelium. At this point it is totally unclear as to whether any of these proteins is involved in the maintenance of the stem cells. Interestingly, several of the proteins are metabolic enzymes including $\alpha$-enolase, ${ }^{13.23}$ cytochrome oxidase, ${ }^{24} \mathrm{Na}^{+} / \mathrm{K}^{+}$-ATPase ${ }^{25}$ and carbonic anhydrase, ${ }^{26}$ suggesting that limbal basal cells may be more meta- 
Table I. Proteins preferentially localised to limbal basal cells

\begin{tabular}{ll}
\hline Protein & Reference \\
\hline$\alpha$-enolase & 13,23 \\
EGF receptor & 31 \\
Cytochrome oxidase & 24 \\
$\mathrm{Na}^{+} / \mathrm{K}^{+}$-ATPase & 25 \\
Carbonic anhydrase & 26 \\
Keratin 19 & 27,28 \\
Vimentin & 27,28 \\
Metallothionein & 33 \\
\hline
\end{tabular}

bolically active than cells in the central cornea. This is somewhat incongruent with the concept that stem cells are relatively inactive and biochemically primitive. One explanation for this seeming contradiction is that only a small portion of the limbal basal cells are actually stem cells. In the blood system only $0.4 \%$ of the cells are thought to be stem cells ${ }^{2}$ and in the intestine $0.5-4 \%$ of the cells are considered stem cells. ${ }^{3}$ In the cornea, approximatly $10 \%$ of the limbal basal cells are label-retaining. ${ }^{6}$ Thus, the limbus may contain a gradient of undifferentiated cells ranging from 'true' stem cells to more mature TA cells. These TA cells, which are proliferating at a higher rate than the stem cells, may be the cells expressing high levels of the metabolic enzymes.
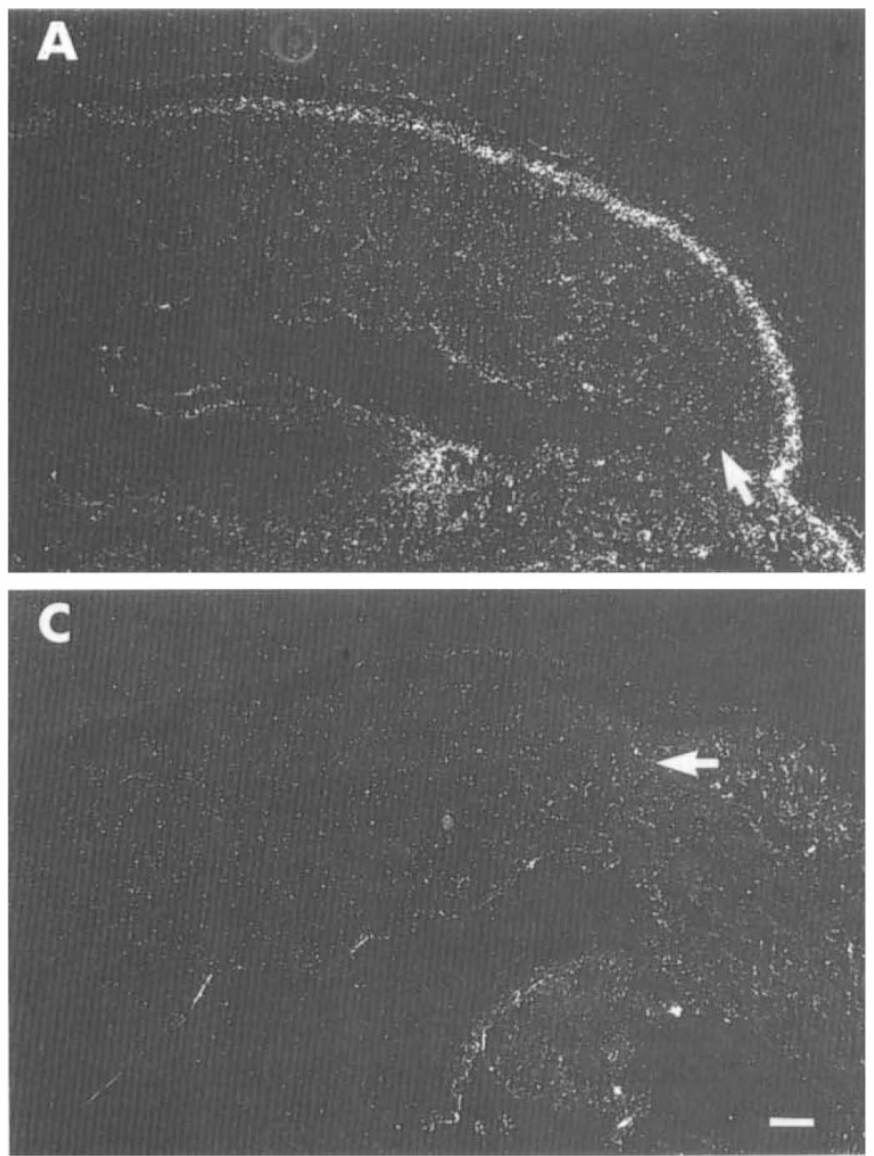

In addition to the metabolic enzymes, two components of intermediate filaments - vimentin and keratin 197,28 have been localised in the limbus. Cells expressing both proteins are found in positions consistent with cells retaining thymidine label in other reports. ${ }^{6}$ Since intermediate filaments are involved in the maintenance of cell architecture, it is possible that the presence of these proteins may somehow be involved in the anchorage of stem cells into a certain microenvironment. Whether vimentin and keratin 19 are localised in the stem cells or early TA cells is not clear, as the proteins show a similar localisation to the metabolic enzymes.

\section{$\alpha$-ENOLASE AND EGF RECEPTOR}

In 1992 we reported on the development of a monoclonal antibody (4G10.3), specific to a $50 \mathrm{kDa}$ protein, that immunolocalised to the limbal basal cells in rat, rabbit and human corneas (Fig. 1). ${ }^{13}$ This antibody showed reciprocal binding with the monoclonal antibody AE5, suggesting that $4 \mathrm{G} 10.3$ was a marker of undifferentiated corneal epithelial cells. Using this antibody, we showed that following a central corneal epithelial debridement, the number of limbal basal cells binding 4G10.3 doubled 48 hours after wounding and returned to normal levels by 72
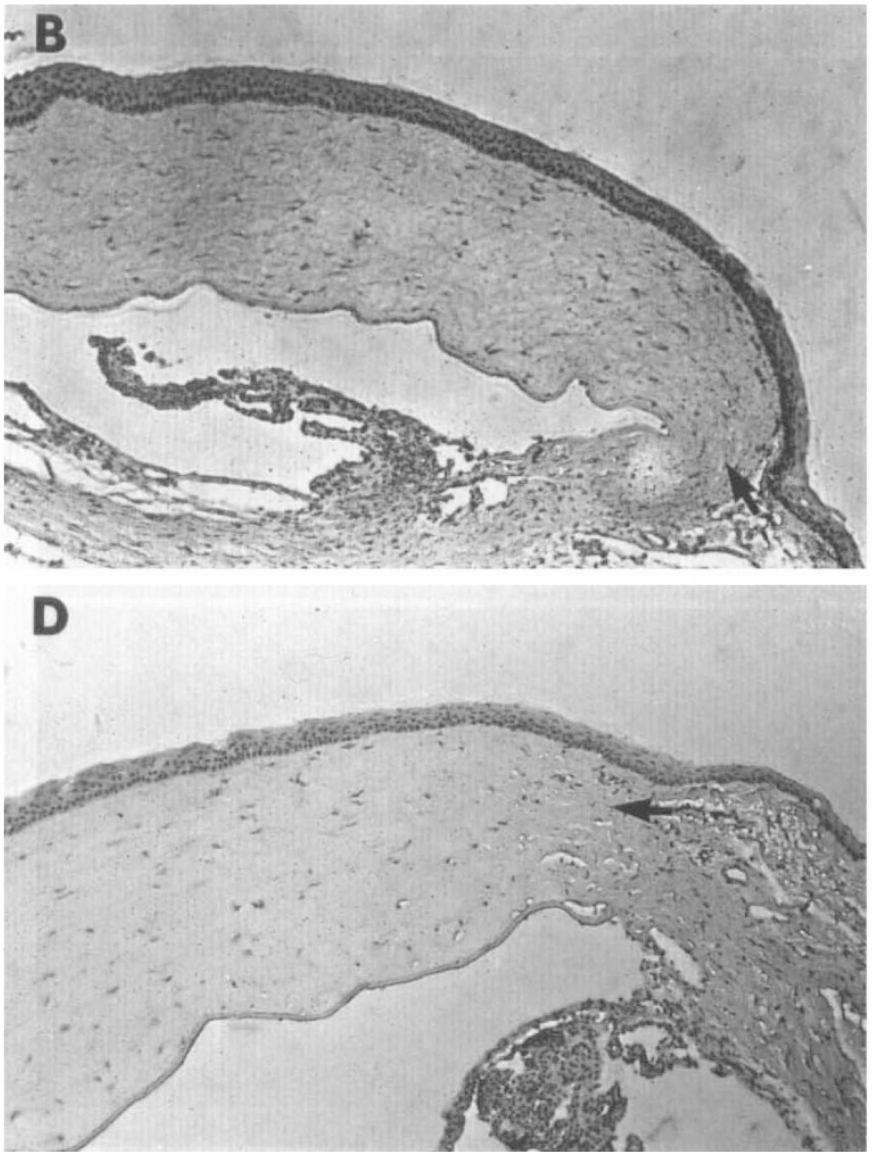

Fig. 4. Autoradiography of ${ }^{125}$ I-labelled epithelial growth factor (EGF). (A) Dark-field autoradiograph shows ${ }^{125}$ I-labelled EGF binding to adult rat cornea. High levels of silver grains in the limbal epithelial region diminish towards the central cornea. $(B) B$ rightfield micrograph of the same area as in (A). (C) Dark-field autoradiograph shows ${ }^{125}$ I-labelled EGF binding to adult rat cornea following incubation with 100-fold excess of unlabelled EGF. Note the low levels of silver grains over the epithelium. (D) Bright-field micrograph of the same area as in $(C)$. A rrows indicate the direction of central cornea. Scale bar represents $50 \mu \mathrm{m}$. (From Zieske and Wasson $^{3 l}$ with permission.) 

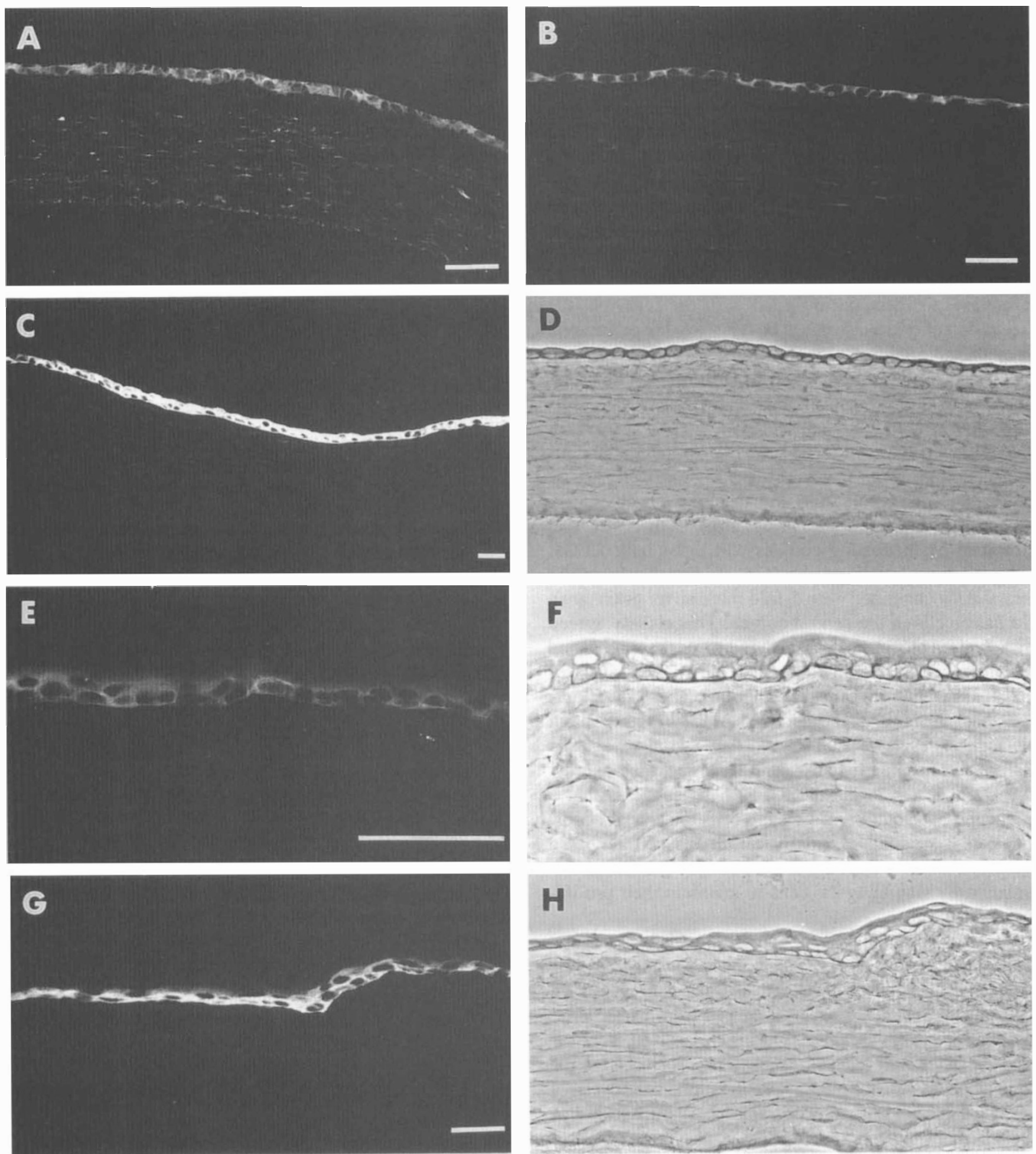

Fig. 5. Immunolocalisation EGFR in corneas of developing rats at $(A) 1,(B) 4$ and $(C) 7$ days of age. (D) Phase-contrast micrograph of the area shown in $(B)$. Note the one or two lavers of epithelial cells. $(E)$ Central cornea, 10 day's of age. $(F)$ Phase-contrast micrograph of the area shown in $(E)$. Note the multilavered epithelium. $(G)$ Limbal region, 10 days of age. Basal cells maintain an intense anti-EGFR immunoreaction. (H) Phase-contrast micrograph of the area show'n in (G). Scale bars represent $50 \mu m$. (From Zieske and Wasson $^{31}$ with permission.)

hours. These data suggested that these cells underwent one round of cell division following wounding, as might be expected for epithelial stem cells. We subsequently identified the $50 \mathrm{kDa}$ antigen of $4 \mathrm{G} 10.3$ as $\alpha$-enolase, a glycolytic enzyme. ${ }^{23}$ In addition to our wound-healing studies, we used 4G10.3 to localise undifferentiated 'stem-like' cells during corneal epithelial development. ${ }^{29}$ In the rat, a large portion of epithelial development occurs between the time of birth and eyelid opening (12-14 days). During this time, the epithelium matures from a one- to two-layer 
tissue to a multilayered stratified epithelium similar to that seen in adult rats. We found that $\alpha$-enolase was localised in basal cells across the entire cornea prior to eyelid opening. During this time, the cells are mitotically active. Between 10 and 14 days after birth, the epithelium rapidly stratifies and $\alpha$-enolase is no longer present in central cornea, becoming sequestered in the limbal basal cells. We interpreted these data as indicating that during development, highly proliferative undifferentiated basal cells are present across the cornea, and that following stratification these stem-like cells become confined to the limbal zone.

Following the identification of the $50 \mathrm{kDa}$ protein as $\alpha$-enolase, we became intrigued with the idea that the expression of $\alpha$-enolase might be related to the expression of epithelial growth factor (EGF) receptor. This concept was based on the findings that EGF stimulates the synthesis of $\alpha$-enolase in fibroblasts. ${ }^{30}$ On the basis of this conjecture we immunolocalised EGF receptor (EGFR) in both human (Fig. 3) and rat corneas. ${ }^{31}$ We found that antibody binding to EGFR was present in basal cells across the adult cornea but was more intense in the limbal zone. To confirm this finding, expression of EGFR was also examined by incubating corneas with ${ }^{125}$ I-labelled EGF, followed by autoradiography (Fig. 4). Basal cells in the limbal zone contained 4- to 5-fold more silver grains than did basal cells in the central cornea. This closely agreed with western blot analysis, which indicated that limbal and peripheral corneal epithelium 4.8-fold higher levels of EGFR than central corneal epithelium. These data indicated that the undifferentiated cells in the limbus contain the highest levels of EGFR, and that as the basal cells mature and migrate towards central cornea, they express lower and lower levels of EGFR. This suggests that a gradient exists, ranging from stem cells to early TA cells, then late TA cells and, finally, terminally differentiated cells, and that high levels of EGFR may inhibit differentiation by signalling the cells to maintain their proliferative potential.

We also examined EGFR expression in the neonatal rat corneal epithelium (Fig. 5). In the rat, during the time between 7 days after birth and eyelid opening (12-14 days) the number of cell layers increases from 1.6 at 7 days to 4.7 after eyelid opening. ${ }^{32}$ During this period, as is the case with $\alpha$-enolase, EGFR is seen in basal cells across the cornea at day 7 . Following stratification, the levels of EGFR in central cornea drop rapidly. Again, these data suggest that undifferentiated cells express high levels of EGFR and that cell maturation occurs concurrently with a lowering of EGFR levels. The combination of the limbal concentration of EGFR in adult cornea and the alterations in EGFR levels during development, led us to propose the hypothesis that stem cells of corneal epithelium express high levels of growth factor receptors to help them maintain their proliferative potential and avoid entering the pathway of terminal differentiation.

\section{CONCLUSIONS}

Recently a wealth of information has been reported that demonstrates that limbal basal cells have unique properties compared with central corneal epithelial cells. This evidence is strongly supportive of the limbal localisation of the corneal epithelial stem cells. These reports also indicate that the limbus may provide a niche for stem cell maintenance. However, a great deal of research is still required to determine the mechanisms involved in the perpetuation of stem cells in the eye.

Key words: Corneal epithelium, EGF receptor, Limbus, Microenvironment, Stem cell, Terminal differentiation.

\section{REFERENCES}

1. Hall PA, Watt FM. Stem cells: the generation and maintenance of cellular diversity. Development 1989;106:619-33.

2. Potten CS, Morris RJ. Epithelial stem cells in vivo. J Cell Sci 1988;10(Suppl):45-62.

3. Gordon JI, Schmidt GH, Roth KA. Studies of intestinal stem cells using normal chimeric, and transgenic mice. FASEB J 1991:6:3039-50.

4. Schermer A, Galvin S, Sun T-T. Differentiation-related expression of a major $64 \mathrm{~K}$ corneal keratin in vivo and in culture suggests limbal location of corneal epithelial stem cells. J Cell Biol 1986; 103:49-62.

5. Davanger M, Evensen A. Role of the pericorneal papillary structure in renewal of corneal epithelium. Nature 1971;229: $560-1$.

6. Cotsarelis G, Cheng S-Z, Dong G, Sun T-T, Lavker RM. Existence of slow-cycling limbal epithelial basal cells that can be preferentially stimulated to proliferate: implications on epithelial stem cells. Cell 1989;57:201-9.

7. Ebato B, Friend J, Thoft RA. Comparison of central and peripheral human corneal epithelium in tissue culture. Invest Ophthalmol Vis Sci 1987;28:1450-6.

8. Ebato B, Friend J, Thoft RA. Comparison of limbal and peripheral human corneal epithelium in tissue culture. Invest Ophthalmol Vis Sci 1988;29:1533-7.

9. Lindberg K, Brown ME, Chaves HV, Kenyon KR, Rheinwald JG. In vitro propagation of human ocular surface epithelial cells for transplantation. Invest Ophthalmol Vis Sci 1993;34:2672-79.

10. Chen JJY, Tseng SCG. Abnormal corneal epithelial wound healing in partial-thickness removal of limbal epithelium. Invest Ophthalmol Vis Sci 1991;32:2219-33.

11. Huang, AJW, Tseng SCG. Corneal epithelial wound healing in the absence of limbal epithelium. Invest Ophthalmol Vis Sci 1991;32:96-105.

12. Kenyon KR, Tseng SC. Limbal autograft transplantation for ocular surface disorders. Ophthalmology 1989;96:709-22.

13. Zieske JD, Bukusoglu G, Yankauckas MA. Characterization of a potential marker of corneal epithelial stem cells. Invest Ophthalmol Vis Sci 1992;33:143-52.

14. Wei ZG, Wu RL, Lavker RM, Sun T-T. In vitro growth and differentiation of rabbit bulbar, fornix and palpebral conjunctival epithelia: implications on conjunctival epithelial transdifferentiation and stem cells. Invest Ophthalmol Vis Sci 1993;34:1814-28.

15. Schofield R. The stem cell system. Biomed Pharmacother 1983;37:375-80.

16. Charbord P. Communication between stem cells and the hematopoietic microenvironment: experimental data and models of interaction. Rev Fr Transfus Hemobiol 1992;35: $335-632$.

17. Gipson IK. The epithelial basement membrane zone of the limbus. Eye 1989;3:132-40.

18. Kolega J, Manabe M, Sun T-T. Basement membrane heterogeneity and variation in corneal epithelial differentiation. Differentiation 1989;42:54-63. 
19. Kruse FE, Tseng SCG. Growth factors modulate clonal growth and differentiation of cultured rabbit limbal and corneal epithelium. Invest Ophthalmol Vis Sci 1993;34: 1963-76.

20. Kruse FE, Tseng SC. Proliferative and differentiative response of corneal and limbal epithelium extracellular calcium in serum-free clonal cultures. J Cell Physiol. 1992;151: 347-60.

21. Kruse FE, Tseng SCG. A tumor promoter-resistant subpopulation of progenitor cells is larger in limbal epithelium than in corneal epithelium. Invest Ophthalmol Vis Sci 1993; 34:2501-11.

22. Watt FM. Epidermal stem cells in culture. J Cell Sci 1988; 10(Suppl):85-94.

23. Zieske JD, Bukusoglu G, Yankauckas MA, Wasson ME, Keutmann HT. $\alpha$-Enolase is restricted to basal cells of stratified squamous epithelium. Dev Biol 1992;151:18-26.

24. Hayashi K, Kenyon KR. Increased cytochrome oxidase activity in alkali-burned corneas. Curr Eye Res 1988;7: 131-8.

25. Lutjen-Drecoll E, Steuhl P, Arnold WH. Morphologische besonderheiten der conjunctiva bulbi. In: Marquardt R, editor. Chronische conjunctivitis-trockenes Auge. Berlin: Springer 1982:25-34.

26. Steuhl K-P, Thiel H-J. Histochemical and morphological study of the regenerating corneal epithelium after limbus-tolimbus denudation. Graefes Arch Clin Exp Ophthalmol 1987;225:53-8.

27. Kasper M. Patterns of cytokeratins and vimentin in guinea pig and mouse eye tissue: evidence for regional variations in intermediate filament expression in limbal epithelium. Acta Histochem (Jena) 1992;93:319-32.

28. Lauweryns B, van den Oord JJ, De Vos R, Missotten L. A new epithelial cell type in the human cornea. Invest Ophthalmol Vis Sci 1993;34:1983-90.

29. Chung E-H, Bukusoglu G, Zieske JD. Localization of corneal epithelial stem cells in the developing rat. Invest Ophthalmol Vis Sci 1992;33:2199-206.

30. Nikaido T, Bradley DW, Pardee AB. Molecular cloning of transcripts that accumulate during the late G1 phase in cultured mouse cells. Exp Cell Res 1991;192:102-9.

31. Zieske JD, Wasson M. Regional variation in distribution of EGF receptor in developing and adult corneal epithelium. J Cell Sci 1993;106:145-52.

32. Watanabe H, Tisdale A, Gipson IK. Eyelid opening induces expression of a glycocalyx glycoprotein of rat ocular surface epithelium. Invest Ophthalmol Vis Sci 1993;34:327-38.

33. Lauwryns B, van den Oord JJ, Missotten L. The transitional zone between limbus and peripheral cornea. Invest Ophthalmol Vis Sci 1993;34:1991-9. 